\title{
Rompendo obstáculos para a implantação de escritório de projetos em empresa de base tecnológica
}

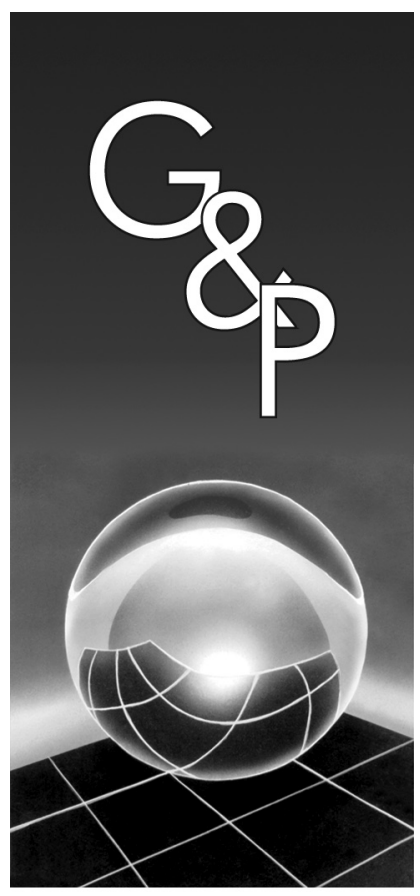

\author{
Sanderson César Macêdo Barbalho \\ Daniel Capaldo Amaral \\ Tiago Sanches Kernbichler \\ Eduardo Henrique Richter \\ Larissa Torres
}

\begin{abstract}
Resumo
Esse artigo apresenta o caso da criação de um escritório de projetos (Project Management Office - PMO) em uma indústria médica de médio porte que passou a desenvolver produtos para o setor espacial. Descreve como a entrada no novo segmento impulsionou a adoção de práticas de gestão de projetos $(G P)$ e como o equacionamento das tensões resultantes dessas práticas levou ao surgimento de um PMO na empresa. Apresenta levantamento com membros das equipes de projeto, os quais foram questionados quanto à efetividade das práticas de gestão sobre os resultados dos projetos. Os dados confirmam a bibliografia quanto a tensões próprias de PMEs de base tecnológica com relação à introdução de ferramentas gerenciais e adicionam duas contribuições: descrevem como o equacionamento das tensões existentes sobre o PMO pode contribuir para sua consolidação e demonstram que a introdução de atividades de caráter mais operacional pode melhorar a forma pela qual os times de projeto avaliam o desempenho do PMO.
\end{abstract}

Palavras-chave: Empresas de alta tecnologia. Desenvolvimento de produtos. Escritório de projetos.

\section{Introdução}

A adoção de práticas avançadas de gestão de projetos (GP) depende da existência de um mínimo de infraestrutura de apoio aos gerentes e equipes de projeto, tais como padronização, recursos e sistemas de informação. As empresas têm criado estruturas organizacionais específicas para esse fim, as quais se tornaram conhecidas no mundo corporativo como escritório de projetos e pela sigla em inglês PMO (Project Management Offices). O escritório de projetos, segundo (CRAWFORD, 2002), é a estrutura organizacional estabelecida para facilitar as atividades da gestão de projetos e trazer melhorias ao próprio processo de gestão da organização por meio da gestão do portfólio e do alinhamento de projetos com a estratégia corporativa.

A implantação deste modelo organizacional é um tema que merece atenção, devido: à dificuldade em dimensioná-la apropriadamente em termos de tamanho, padrões, procedimentos e formação de pessoas qualificadas (VALERIANO, 2001; CRAWFORD, 2002; KERZNER, 2006); às barreiras culturais envolvidas (CRAWFORD, 2002; MARTINS et al., 2005); e mesmo a questões externas como a estrutura de decisão, estratégia e gestão de portfólio de projetos da empresa (LAMBERT, 2006). Pesquisas recentes mostram que os PMOs são estruturas altamente flexíveis e que comumente são reestruturadas para adequar sua atuação às mudanças na estratégia empresarial (HOBBS; AUBRY; THUILLIER, 2008).

As empresas de alta tecnologia apresentam projetos complexos e geralmente convivem com vários deles de maneira paralela. Porém, os obstáculos para a adoção de PMO são especialmente importantes. Recursos de apoio são muitas vezes vistos como desperdício e as técnicas de gestão de projetos como métodos "burocratizantes" que diminuem a criatividade e velocidade (ALI et al., 1995; CALDERINI; CANTAMESSA, 1997). A bibliografia aponta a gestão de projetos como uma das áreas de maior problema e na qual as empresas desejavam investir e melhorar suas práticas (TOLEDO et al., 2007).

O presente trabalho apresenta o caso de uma empresa de alta tecnologia cuja atuação era voltada para o desenvolvimento de equipamentos médicos e com forte resistência ao emprego 
de técnicas de gerenciamento de projeto. O desenvolvimento de um produto para o segmento aeroespacial implicou na necessidade de introdução de ferramentas de GP devido a exigências contratuais. Estas práticas se estabeleceram nos produtos da área e aos poucos se difundiram para os demais negócios da empresa consolidando um PMO nível 1 com algumas características de escritórios nível 2 (ver item 2.2).

$\mathrm{O}$ artigo descreve o caso partindo das tensões enfrentadas para a implantação de práticas de GP e como elas foram abordadas de maneira a não apenas suplantá-las, mas implantar um PMO e consolidá-lo dentro da estrutura organizacional da empresa. Apresenta-se o resultado de um levantamento da percepção de satisfação dos funcionários em relação às práticas e ferramentas de gestão de projetos implementadas. Verifica-se que o perfil de satisfação tem relação direta com padrões de atuação mais focados no serviço prestado às equipes de projeto em contraposição a atividades com caráter de maior controle e monitoramento do trabalho.

Do ponto de vista metodológico, o trabalho se configura como uma pesquisa-ação, segundo Thiollent (1997). Emergiu de uma integração entre o pessoal envolvido com as práticas de gestão de projetos na empresa aqui apresentada e um grupo de pesquisa em GP de uma universidade brasileira. Buscou-se seguir um conjunto de regras para controle da subjetividade dos pesquisadores sobre os dados levantados, conforme descritas em Thiollent (1994). Do ponto de vista técnico, os dados foram levantados por meio de questionário estruturado com perguntas fechadas e abertas, assim como por meio de observação participante (SERVA; JÚNIOR, 1995), a qual, entretanto, foi utilizada apenas para subsidiar a análise dos dados. Uma vez que se trata da descrição de práticas em uma empresa apenas, pode-se classificá-lo como estudo de caso holístico, segundo Yin (2004).

A seção seguinte apresenta os fundamentos teóricos do trabalho: a teoria sobre o desenvolvimento de produtos em pequenas e médias empresas de base tecnológica e a fundamentação sobre Escritório de Projetos. A seção 3 apresenta o trabalho de implantação de práticas de gestão de projetos e do escritório de projetos estruturado. A seção 4 apresenta o levantamento da satisfação dos usuários com as práticas de GP. A seção 5 apresenta as considerações finais do trabalho.

\section{Referencial teórico}

\subsection{Desenvolvimento de produtos em Pequenas e Médias Empresas - PMEs de base tecnológica}

Knight (2001) mostra que o sucesso de Pequenas e Médias Empresas (PMEs) americanas na internacionalização de suas atividades tem relação com a postura inovadora e visão proativa de seus dirigentes quanto ao mercado global. Man et al. (2002) apresenta evidências de que a distinção entre o sucesso e o fracasso de pequenas empresas está fortemente relacionada com "...a experiência, conhecimento e habilidades dos proprietários e trabalhadores". Esses estudos ilustram um aspecto forte nas PMEs de base tecnológica que é a dependência que elas têm quanto às pessoas, especialmente seus proprietários, uma vez que seus processos são, comumente, pouco definidos e padronizados.

Starbek e Grum (2002) descrevem uma pesquisa realizada em uma pequena empresa eslovena de implementos agrícolas que buscou reestruturar o seu Processo de Desenvolvimento de Produtos (PDP) tomando por base a organização desse processo em times e adoção de práticas de gestão de projetos. March-Chordà, Gunasekaran e Lloria-Aramburo (2002) abordaram um grande conjunto de PMEs quanto ao atendimento ou não de uma lista de melhores práticas descritas na bibliografia como fatores críticos de sucesso no PDP. Os autores identificaram um baixo grau de utilização das melhores práticas, o qual seria decorrente dos altos custos e tempos de ciclo dos projetos de desenvolvimento.

Calderini e Cantamessa (1997) apresentam um estudo com 21 empresas de pequeno e médio porte localizadas nos arredores de Turin, Itália. Os autores categorizaram as empresas em três "tipos" em função da base de sua competição em termos de produto: (A) empresas que ofereciam produtos de prateleira; (B) empresas oferecendo produtos customizados e competindo com base na sua capacidade de entregar valor ao mercado; e (C) subcontratados verticalmente integrados com seus clientes (no caso a FIAT). Segundo os autores, as empresas do grupo B apresentavam-se na "fronteira da excelência" na gestão do PDP, eram as empresas mais equilibradas em termos de adoção de metodologias e tecnologias de suporte ao projeto de novos produtos e tendiam a não migrar para os outros "tipos". Para essas empresas a adoção de metodologias era vista como "perda de tempo" pelos entrevistados. Por outro lado, as tecnologias relacionadas ao PDP, como Computer Aided Design (CAD)/Computer Aided Manufacturing (CAM), Computer Aided Process Plan (CAPP), Computer Aided Engineering (CAE) entre outras, eram fortemente presentes em empresas do tipo C, porém resultando em alto grau de ociosidade.

Ali et al. (1995) relatam um estudo realizado com proprietários de 73 PMEs de alta tecnologia americanas com o objetivo de verificar o impacto do grau de inovação de um produto e de sua complexidade técnica no ciclo de desenvolvimento dele, assim como em seu tempo de retorno. Os autores chegaram a uma média de 18,7 meses de duração dos projetos com uma média de 5 pessoas envolvidas ao longo desse tempo. O tempo de retorno (payback) médio foi de 17,4 meses.

Jugend (2006) estuda empresas de base tecnológica paulistas e ressalta a importância do conhecimento acumu- 
lado pelos dirigentes da empresa como principal mecanismo de inovação. Especialmente em relação à gestão de projetos, o autor identificou uma contradição uma vez que os entrevistados demonstram um receio de que a adoção de técnicas de gestão impacte negativamente na agilidade com a qual os projetos são desenvolvidos, mas, por outro lado, apontam a gestão de projetos como um problema a ser superado. Quase a totalidade dos pesquisados admitiu ter planos de investir em softwares e treinamento em GP.

Analisando a implantação de sistemas de informação gerenciais (enterprise resource planning - ERP) em pequenas e médias empresas, Mendes e Escrivão Filho (2007) apontam que a adoção gradual das ferramentas de gestão parece ser o caminho mais adequado às PMEs. Considera-se esse aspecto como sendo determinante na adoção de ferramentas gerenciais complexas, dentre as quais os PMOs, conforme abordado no presente trabalho.

Toledo et al. (2007) pesquisa PMEs paulistas com o objetivo de identificar direcionadores de sucesso do seu PDP. Os resultados apontam para a importância de um detalhado trabalho de levantamento e especificação de requisitos, a gestão das equipes de projeto e a documentação e arquivo técnico dos projetos como direcionadores. Toledo et al. (2008) apresenta uma análise comparativa entre empresas das áreas de equipamentos médicos e de automação. Os autores verificam que algumas empresas gerenciam os projetos de novos produtos de maneira totalmente informal sugerindo não haver “.... necessidade de formalização do processo de desenvolvimento de projetos". Esse comportamento, entretanto, não se generaliza, especialmente para empresas da área médica sujeitas à regulação da Agência Nacional de Vigilância Sanitária (ANVISA). Os resultados apontam para ambos os tipos de empresa, uma forte demanda por gerenciar com esmero as interfaces com o cliente final assim como a necessidade de prover habilidades gerenciais aos líderes de projeto, especialmente relacionadas à motivação das equipes.

\subsection{Escritórios de projeto}

\subsubsection{Definição e tipologias}

Vários autores, como Valeriano (2001), Kerzner (2006) e Heldman (2003), apresentam o conceito de escritório de projetos empregando diferentes nomes: escritório estratégico de projetos; escritório de apoio ao projeto; escritório de apoio ao programa; escritório de gerência de projeto; e escritório de apoio à gerência de projeto; e escritório do programa. Segundo os autores, os PMOs se originaram em meados dos anos 60 nos grandes projetos militares, aeroespaciais e de construção civil.

No final da década de 70, até meados da década de 80 , com o surgimento dos primeiros softwares de gestão, o escritório expandiu sua cobertura inicial para outros projetos de áreas diferentes. Membros das áreas funcionais, não especialistas em projetos, foram alocados nos escritórios que assumiram a função de suporte aos projetos. No final dos anos 80 e meados da década de 90 , as ferramentas de gestão sofreram uma revolução facilitando o trabalho de controle e suporte. A atuação dos escritórios em várias empresas evoluiu de projetos relativamente simples e isolados para ambientes multiprojetos e projetos complexos; de funções de controle e suporte para gestão global alinhada às estratégias organizacionais.

Para Crawford (2002), um escritório pode ser tão simples como umas poucas pessoas preparando e mantendo cronogramas, até várias pessoas realizando planejamento, informes, monitoramento de projetos etc. O PMO cresce com as necessidades da organização. Os modelos de PMO sugeridos pela autora, os quais classificam os escritórios de projetos segundo níveis, são amplamente utilizados na bibliografia científica (Figura 1).

O nível 1 do escritório de projetos é característico de grandes e complexos projetos únicos, sendo o escritório totalmente voltado ao projeto que o criou. O nível 2 de escritório de projetos, destinado a uma unidade de negócios específica, tem a importante característica de realizar a gestão de recursos da unidade; assim, é necessário criar métricas para priorização dos vários projetos existentes no departamento que competem por recursos entre si.

O nível 3 é uma extensão do anterior, no entanto, gerencia projetos de todas as unidades de negócio da organização. Esta estrutura, portanto, permite viabilizar projetos e programas alinhados às estratégias da organização e não somente de uma unidade de negócio.

Hobbs e Aubry (2007) realizaram extenso estudo analítico acerca das atividades dos PMOs. Foram analisadas a presença e o grau de importância de 27 diferentes funções/papéis atribuídos aos PMOs. Essas funções/papéis foram agrupadas com base em análise fatorial gerando os seguintes grupos: (1) atividades de monitoramento e controle do desempenho dos projetos; (2) desenvolvimento de competências e metodologias de gestão de projetos; (3) gerenciamento multiprojeto; (4) gestão estratégica; e (5) aprendizagem organizacional. Esse conjunto de tarefas pode ser considerado clássico na bibliografia sobre PMOs, entretanto, os autores identificaram outras atividades consideradas importantes pelos pesquisados, mas que não foram agrupadas por razões de coerência conceitual: (6) execução de tarefas especializadas para os gerentes de projeto; (7) gerenciamento das interfaces com clientes; e (8) recrutamento, seleção, avaliação e determinação de salários dos gerentes de projeto

\subsubsection{Pesquisas acerca de escritórios de projetos}

Dai e Wells (2004) comparam práticas de gestão de projetos em empresas com e sem PMOs. Os autores identificaram práticas mais efetivas de GP nas empresas com PMOs, especialmente quanto ao registro de lições aprendidas e à aplicação de metodologias e técnicas de 


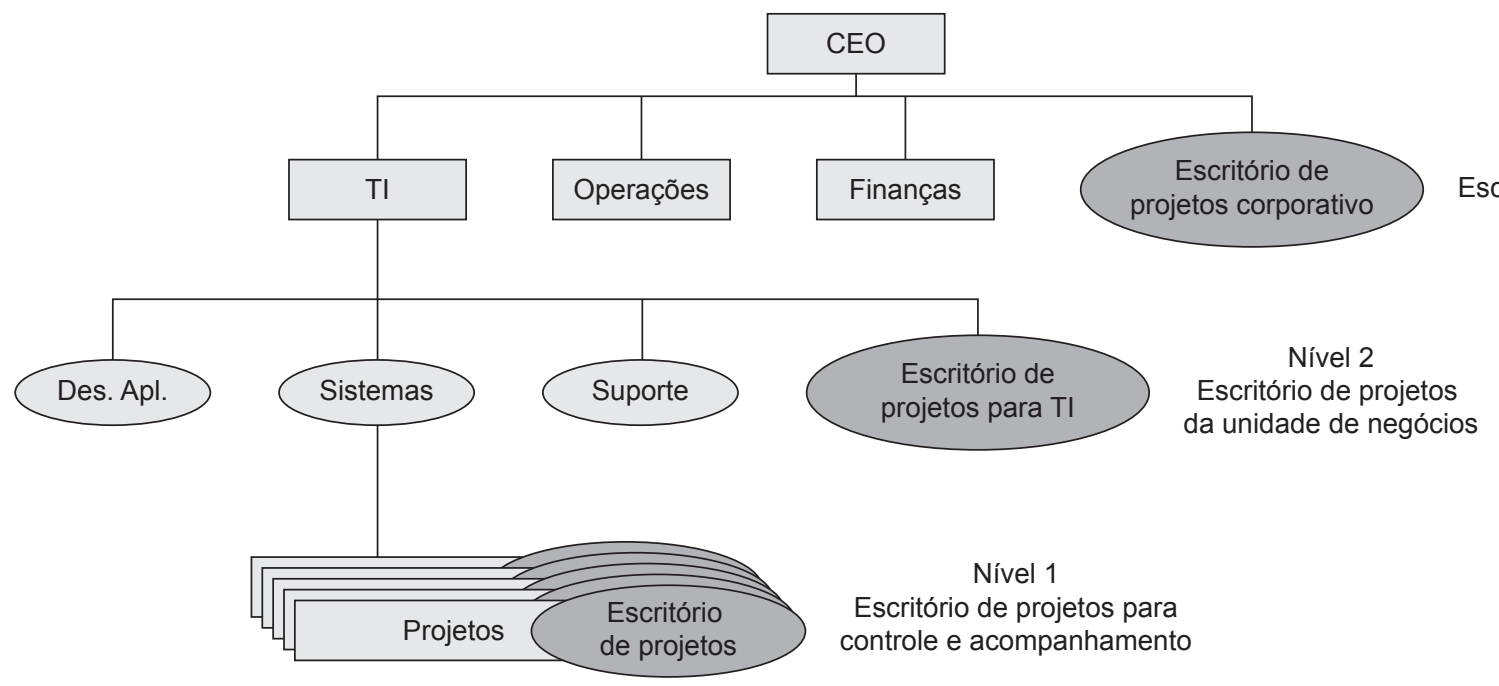

Nível 2

scritório de projetos estratégico

Figura 1. Níveis de atuação do escritório de projetos (CRAWFORD, 2002).

GP. Martins et al. (2005) analisam a fusão de empresas de telefonia celular no Brasil e demonstram como as funções e responsabilidades do escritório de projetos foram sendo incrementadas ao longo do tempo em função dos resultados alcançados no desempenho dos projetos, assim como do suporte da alta gerência na demarcação do espaço político do PMO dentro da empresa. Carvalho et al. (2005) discutem diferentes modelos de maturidade em gestão de projetos e, ao longo de seu estudo, verificaram empiricamente que, mesmo havendo apoio da alta gerência para a implantação de práticas de GP, barreiras no nível gerencial médio impediam a disseminação da cultura de gestão de projetos.

Mullaly (2006) estuda o impacto das práticas de gestão de projetos sobre os resultados de negócio de um grande conjunto de empresas americanas e canadenses. $\mathrm{O}$ autor relaciona melhor desempenho com o nível de maturidade das empresas em GP, porém constata que muitos dos resultados conseguidos ao longo dos anos de estudo dependiam de haver um profissional dedicado à implantação da GP (um champion) e quando esse profissional se desligava da empresa havia uma regressão significativa nos resultados vinculados a tais práticas. Crawford (2006) analisa o conceito de organização para o gerenciamento de projetos e sugere que a consolidação da GP passa pela constituição de PMOs. Estes teriam a função de incrementar e a de manter o nível de maturidade em GP da empresa.

Rodrigues, Rabechini Jr. e Csillag (2006) realizam estudo descritivo que enfoca a relação entre PMOs e a maturidade da GP nas empresas. Os autores observam que os PMOs pesquisados apresentam baixo grau de aderência aos modelos teóricos estabelecidos, conforme descrito no item anterior. Segundo os autores, o sucesso dos PMOs está relacionado com seu posicionamento na estrutura hierárquica da empresa, o suporte dado pelos gerentes funcionais ao PMO nas tarefas interdepartamentais e o sucesso dos projetos.
Maximiano e Anselmo (2006) estudam a implantação de um escritório de projetos em uma grande empresa da área de telefonia e reportam o suporte da alta gerência como o principal fator crítico de sucesso do PMO. Os autores identificaram que há uma lacuna no que concerne a metodologias viáveis para a quantificação do valor de um PMO. Lambert (2006) argumenta que, embora o conceito de PMO venha sendo estudado e difundido de maneira significativa no meio empresarial, ainda há uma série de dificuldades e um número significativo de fracassos na sua implementação. Entre as dificuldades destacam-se a adoção de metas irrealistas e a interpretação de alguns gerentes e decisores que veem as técnicas de construção de gráficos de gantt e diagramas de revisão e avaliação de programas (Program Evaluation Review Technique - PERT) como mera burocracia.

Aubry, Hobbs e Thiller (2007) consideram que a pesquisa em gestão de projetos tem, comumente, adotado uma postura positivista apresentando dificuldades no que tange ao entendimento de como os PMOs devem ser concebidos e gerenciados em empresas que não trabalham exclusivamente com projetos para atender a seus objetivos de negócio. Para os autores, os PMOs são estruturas que conectam múltiplas dimensões de uma organização e, como tais, não devem ser avaliados apenas quanto a prazos, custo, escopo e desempenho, mas também quanto à coesão e moral das equipes e ao alinhamento estratégico dos projetos. Castro e Carvalho (2007) realizam um estudo de casos múltiplos em empresas de telecomunicações brasileiras nas quais há efetivo uso de práticas de GP, inclusive com implantação de PMOs. Os autores observaram uma lacuna quanto à aferição dos resultados das práticas de GP em todas as empresas pesquisadas, mesmo nas que contavam com PMOs.

Hobbs e Aubry (2007) consideram que a dificuldade conceitual relacionada aos PMOs tem base em: (1) PMOs são 
fenômenos relativamente recentes; (2) há grande variedade de formas e funções para eles; e (3) não há investigação mais sistemática a respeito. Os autores descrevem um estudo com 500 PMOs canadenses, americanos e australianos com o objetivo de levantar seu modus operandi de maneira a caracterizá-los de forma mais assertiva. Para os autores, na média, as atividades de monitoramento e controle do desempenho dos projetos são as mais importantes dentro dos PMOs e há uma correlação direta entre eles e maturidade em GP. Tal relação é descrita como sendo circular: PMOs aumentam a maturidade em GP da empresa. A maturidade reforça o trabalho do $\mathrm{PMO}$ e assim sucessivamente.

Julian (2008) analisa o papel dos líderes de PMOs na transferência de conhecimento entre projetos. $\mathrm{O}$ autor verificou que, embora ocorra, a transferência é realizada por meio de intervenções em projetos que sofrem problemas de prazo, custo ou escopo e que essa prática estimula a criação de ambientes defensivos. Ao final há pouca aprendizagem de fato. Hobbs, Aubry e Thuillier (2008) analisam PMOs como elementos de inovação organizacional. Pesquisando a historia de 11 PMOs ao longo de cerca de 10 anos, os autores verificaram que as empresas reconfiguram seus escritórios a cada 3 ou 4 anos motivados por eventos do contexto social da empresa, eventos internos, filosofia de gestão ou tensões internas da empresa. Os autores mapearam as tensões envolvidas na estruturação dos PMOs pesquisados: (1) econômica - relacionada ao desempenho dos projetos e ao custo do PMO; (2) política relativa especialmente à gestão dos projetos e à comunicação da situação dos prazos e custos para a empresa; (3) relacionamento com o cliente - seja o cliente final do projeto ou seus clientes internos; (4) padronização e flexibilização dos procedimentos do PMO - uma orientação para o negócio resulta que demandas práticas da execução dos projetos muitas vezes exigem flexibilidade não existente no processo gerenciado pelo PMO; e (5) o controle sobre a máquina do projeto - reflete a tensão entre o projeto e a área funcional, especialmente no que tange aos recursos necessários à execução dos projetos. Segundo os autores, a variedade de PMOs encontrados é consequência das respostas que cada empresa dá às tensões acima elencadas e sobre elas incidem ainda os eventos externos ou internos de um dado contexto da firma.

\subsection{Consolidação do referencial teórico}

Sob o ponto de vista do presente trabalho, o referencial analisado permitiu estabelecer um marco conceitual a ser testado ao longo da pesquisa. Do ponto de vista das PMEs de base tecnológica, prevê-se existir um ambiente fortemente dependente do proprietário empreendedor (KNIGHT, 2001; MAN et al., 2002), de quem o suporte para a implantação do PMO é de fundamental importância (MARTINS et al., 2005), o que pode ser facilitado pela demanda que as PMEs de base tecnológica têm quanto a melhorias em GP, especialmente no gerenciamento de equipes e na provisão de habilidades gerenciais para os líderes de projeto (TOLEDO et al., 2008).

A implantação deve se dar de forma adaptada à cultura da empresa (CALDERINI; CANTAMESSA, 1997) e deve refletir uma adoção gradual da ferramenta (MENDES; ESCRIVÃO FILHO, 2007), muito embora deva gerar resultados práticos ao longo de sua implantação (MARTINS et al., 2005; RODRIGUES; RABECHINI Jr.; CSILLAG, 2006). A implantação deve ser acompanhada do monitoramento do valor do PMO para a GP na empresa (MAXIMIANO; ANSELMO, 2006), considerando uma abordagem mais ampla dos resultados do PMO (AUBRY; HOBBS; THILLER, 2007).

Enfim, os eventos e tensões descritos por Hobbs, Aubry, Thuillier, 2008, deveriam ser monitorados, pois poderiam se configurar em obstáculos para a consolidação do escritório de projetos na empresa.

\section{Descrição do trabalho de implantação do escritório de projetos}

\subsection{Caracterização da empresa}

A empresa na qual foi implementado o escritório de projetos foi fundada em 1985 por professores e técnicos de uma das universidades da cidade na qual se localiza. Iniciou suas atividades com a produção de filmes finos especiais e aplicações industriais a laser. Posteriormente entrou nos mercados de defesa, médico-oftálmico e espacial. Suas unidades de negócio são basicamente:

- tratamento de lentes oftálmicas com aplicação de filmes antirrisco e antirreflexo;

- produção de lentes sob encomenda para aplicação industrial;

- produtos industriais: medidor a laser para controle de pneus e multiposicionador laser;

- produtos da área médica: microscópios cirúrgicos oftálmico e odontológico, retinógrafo digital e laser fotocoagulador para cirurgia de retina;

- produtos de defesa: componentes ópticos e sistemas de detecção a laser para a Aeronáutica e o Exército brasileiros; e

- produtos da área espacial: subsistemas para integração em satélites de monitoramento ambiental realizando a captação e o processamento de imagens da Terra. Essa unidade de negócio é gerenciada internamente em conjunto com a de produtos para a defesa.

A empresa compõe-se de quatro diretorias: filmes finos, pesquisa e desenvolvimento, diretoria comercial e diretoria de manufatura. Cada diretoria tem como diretor um dos sócios proprietários da firma. A diretoria de "pesquisa e desenvolvimento" (P\&D) é responsável pelo projeto dos equipamentos, que podem ser médicos ou espaciais. Ela é composta de um grupo de engenharia formado por enge- 
nheiros mecânicos, eletrônicos, de software e físicos e por um grupo de montagem especializada, composto por técnicos em eletrônica e mecânica, responsável pela integração dos equipamentos de defesa desenvolvidos e montagem dos protótipos de equipamentos em desenvolvimento. Ela utiliza serviços especializados das diretorias de filmes finos e de operações industriais.

O escritório de projetos foi montado dentro da diretoria de P\&D da empresa originalmente para atender às demandas de um novo projeto de desenvolvimento do setor aeroespacial, mais especificamente do satélite sino-brasileiro. Nas próximas seções, apresenta-se como são gerenciados os projetos de desenvolvimento de produtos antes e depois da entrada da empresa no setor espacial. Vale ressaltar que, no momento inicial desta pesquisa, a empresa estava a cerca de sete anos desenvolvendo novos produtos apenas para a área médica.

\subsection{Gerenciamento de projetos de novos produtos na área médica da empresa}

A Figura 2 apresenta um esquema representativo do gerenciamento de projetos de novos produtos da área médica na empresa. $\mathrm{O}$ formato de gestão era baseado nas normas ISO 9001, especialmente as cláusulas 7.3.2 até 7.3.7 (conforme identificadas na figura), e nos requisitos específicos imputados pela norma NBR ISO 13485 (2000) que trata do sistema de qualidade específico para projetos de equipamentos médicos. O esquema representado na Figura é resultado da sistematização dos fluxos de atividades prescritos nas cláusulas mencionadas.

O fluxo representado na Figura 2 reproduz um procedimento comumente encontrado em organizações de engenharia. Basicamente, os projetos devem ter requisitos de entrada explícitos e sistematizados de forma a permitir a realização de um planejamento de projeto com identificação das equipes, dos fluxos de informação entre os diferentes atores da empresa e das etapas necessárias aos projetos, suas atividades, prazos e pontos de controle. Esse planejamento deve ser periodicamente revisto pelas denominadas "análises críticas" (ver figura) que seriam decisões go/non go, as quais perduram até que os resultados conseguidos atendam aos requisitos do produto. Quando o projeto passa a cumprir todos seus requisitos de entrada, as normas preveem a realização de duas etapas formais: (1) a "verificação" de projeto, na qual os requisitos são formalmente avaliados sendo documentados os ensaios e os resultados atingidos; e (2) a "validação" do projeto que representa o teste do equipamento junto ao cliente final e sua aprovação. Concluídas as atividades de validação, prevê-se a geração

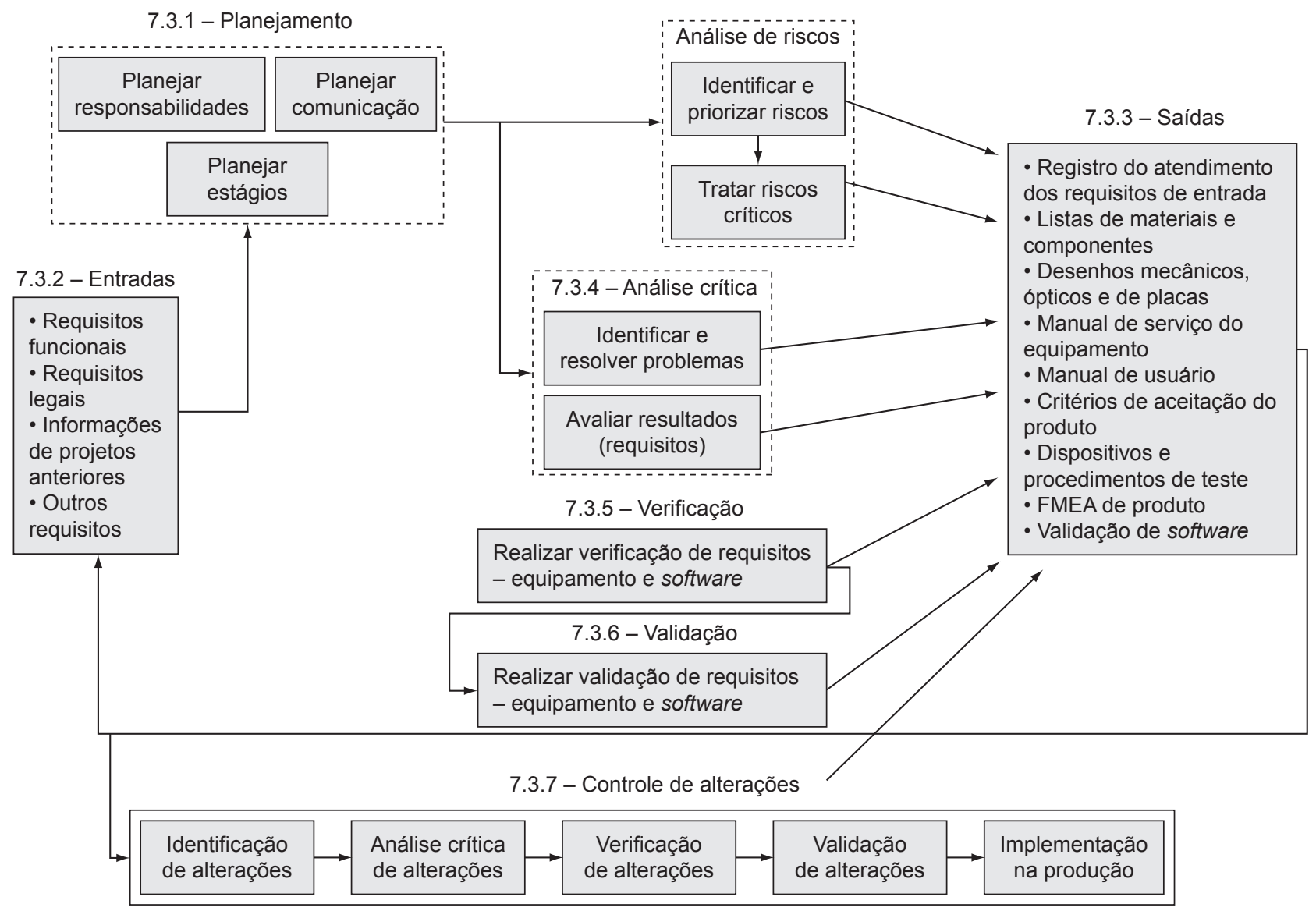

Figura 2. Atividades e Resultados do Tópico 7.3 das ISO 9001 e ISO 13485. 
de um conjunto mínimo de saídas do projeto, conforme identificados no item 7.3.3 da ISO 9001:2000 (vide Figura 2). As normas preveem ainda um conjunto de atividades que devem ser registradas a título de controle de alterações dos projetos.

A descrição acima reflete os requisitos gerais da ISO 9001:2000 para qualquer tipo de projeto de novo produto, enquanto as exigências da norma ISO 13485 envolvem aspectos específicos para equipamentos médicos, tais como obrigatoriedade de "análise dos riscos" decorrentes do uso e operação do produto. Ademais, a ISO 13485 indica a necessidade de que componentes de hardware e de software sejam tratados de maneira diferenciada: devem ser realizados experimentos que validem as funções de softwares que impactam nos principais riscos identificados no projeto.

Embora as saídas do projeto fossem consolidadas em documentação específica, o histórico do projeto, aí incluídos planejamento inicial e suas atualizações, análises críticas, resultados dos testes, controle de configurações dos protótipos fabricados e testados etc., era controlado utilizando-se registros em cadernos de ATAS em formato similar ao utilizado em laboratórios de pesquisa em universidades brasileiras. Do ponto de vista organizacional, nessa configuração inicial, as atividades de gestão de projetos não eram explicitamente colocadas na estrutura organizacional da empresa sendo realizadas a título de assessoria aos projetos em desenvolvimento, conforme ilustra a estrutura organizacional apresentada na Figura 3.

Havia um ceticismo dentro da alta direção com relação às práticas de GP, pelo receio de que inibissem o processo de inovação dentro da empresa, "engessando" os processos e fazendo-a perder seus dois mais importantes diferenciais competitivos: criatividade e inovação. Assim, a empresa limitava-se ao suficiente para obter as certificações de sistemas da qualidade, corroborando com os estudos de Calderini e Cantamessa (1997), quanto às empresas de tipo "B" segundo a classificação dos autores, assim como a de Jugend (2006).

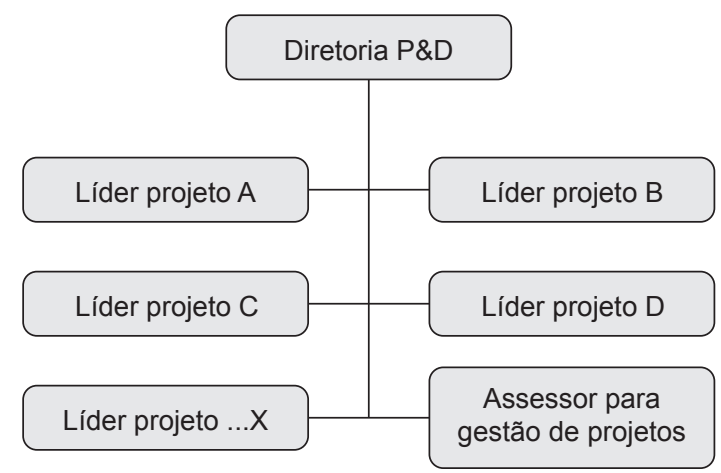

Figura 3. Estrutura organizacional do setor de projetos antes da introdução do PMO.

\subsection{Requisitos dos projetos da área espacial}

O Programa Espacial Brasileiro (PEB) utiliza as normas da Cooperação Europeia para Padronização na Área Espacial (ECSS) como referência para a contratação e gerenciamento das empresas que desenvolvem produtos na área espacial brasileira. Esses padrões são compatíveis com as normas ISO e estabelecem requisitos adicionais para reduzir a probabilidade de erros em projetos espaciais (EUROPEAN COMMISSION FOR SPACE STANDARDIZATION, 2003, p. 3).

A Figura 4 apresenta a estrutura de padrões ECSS. Há três blocos de padrões, ou domínios, designados como "Gerenciamento", "Engenharia" e "Garantia do Produto". Cada um desses blocos é introduzido por um documento de "nível 1" (ECSS-M-00, ECSS-E-00 e ECSS-Q-00) assim como seu conteúdo e a arquitetura do que está definido em seu escopo.

Em linhas gerais:

- padrões ECSS de gerenciamento definem os requisitos a serem aplicados às atividades de gestão de projetos, tais como árvores de produto, estrutura da divisão do trabalho (WBS), formas de organização a adotar, estrutura de gerenciamento de custos e tempo, gestão da configuração e de documentos. Determinam ainda os marcos e revisões de fase do projeto, assim como o conteúdo dos documentos a serem entregues em cada revisão. Eles foram os referenciais originais do Escritório de Projetos constituído;

- padrões dos tipos "Q" e "E" estabelecem requisitos de engenharia e garantia do produto para os quais o PMO deve dar suporte. Padrões tipo "Q" (qualidade) impõem um rigoroso controle ao que denominam de Partes, Materiais e Processos (PMPs) na fabricação dos protótipos. Padrões tipo "E" (engenharia) estabelecem restrições tecnológicas para a aquisição de componentes e materiais a serem utilizados em órbita que tornam os processos de compra, fabricação e montagem bastante complexos.

O conjunto de especificações de engenharia, qualidade e gerenciamento sumarizado gerou a necessidade de realização de determinadas tarefas de apoio gerencial ao longo das etapas do projeto que se iniciaram para atender ao conjunto de documentos gerenciais necessários ao contrato, mas culminaram na consolidação de um PMO. A gestão de projetos na empresa, representada pela Figura do "assessor para gestão de projetos" (Figura 3) não tinha estrutura para realizar os serviços de acompanhamento dos PMPs (Partes, Materiais e Processos) do projeto e do seu impacto nos prazos estabelecidos pelos marcos contratuais, de gerenciamento de custos, de suporte aos processos de compra e fabricação, gerenciamento de árvores de produto e WBS etc. Os projetos da área espacial passaram, portanto, a demandar uma estrutura gerencial mais robusta que o processo de gerenciamento exposto sumariamente na seção anterior. 


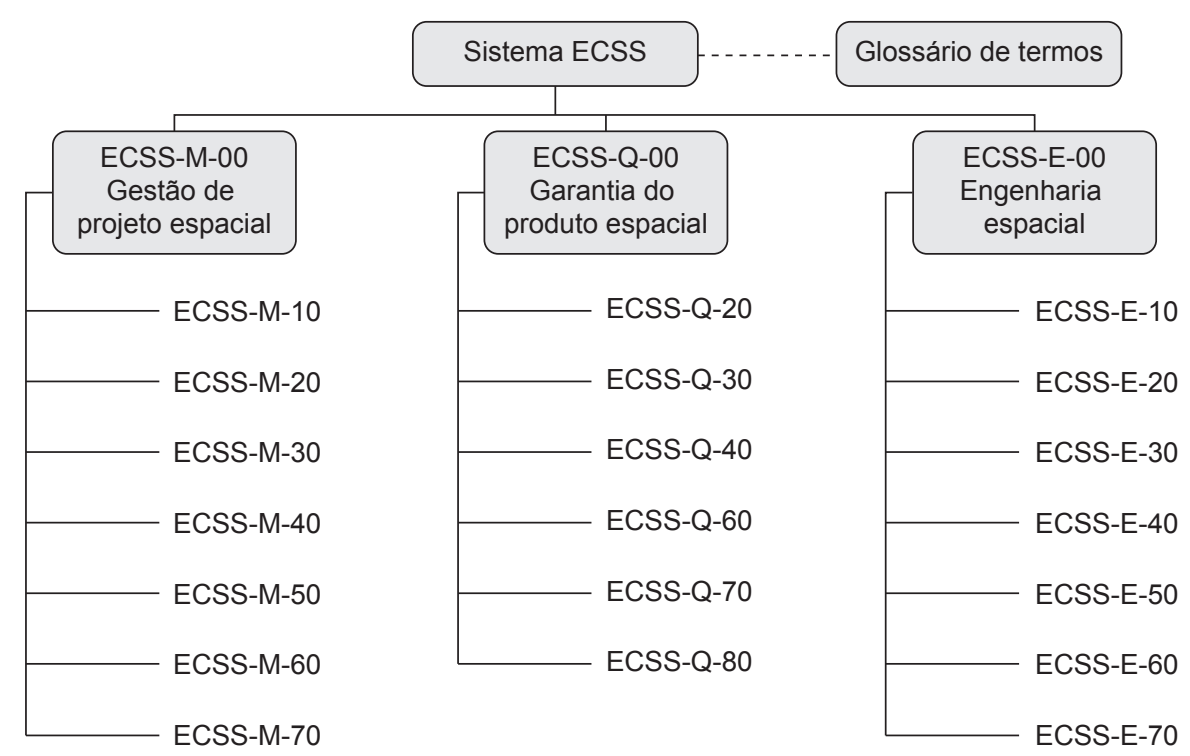

Figura 4. Sistema de padronização ECSS (Fonte: EUROPEAN COMMISSION FOR SPACE STANDARDIZATION, 2003, p.12).

\subsection{Atividades do escritório de gestão de projetos}

Os projetos espaciais demandaram, já desde seu início, a confecção de relatórios de progresso mensais, detalhados e absolutamente necessários sob a óptica do cliente final do projeto - no caso, o Instituto Nacional de Pesquisas Espaciais (INPE). A análise da aplicação do recurso contratado em função dos marcos vindouros e a necessidade de planejamento e controle das atividades de gestão dos prazos e do trabalho a ser realizado passaram a ser vistas como reais necessidades do projeto, sob o ponto de vista da diretoria da empresa, a qual, conforme já mencionado, considerava as atividades de gestão meras formalidades com fins de certificação.

Tornou-se evidente a existência de lacunas apresentadas pela forma de gestão de projetos da unidade de negócio com relação às novas demandas apresentadas pelos projetos da área espacial, conforme apresentado na Tabela 1. Isso motivou o investimento em GP. Na prática, novas atividades foram incorporadas à assessoria de gestão de projetos (Figura 3), que possuía na época um único funcionário, ao mesmo tempo responsável pelo setor.

\subsection{Obstáculos para o estabelecimento de práticas de Gestão de Projetos - GP na empresa}

Uma série de obstáculos surgiu quando da necessidade de implantação das práticas apresentadas na Tabela 1. As barreiras seguiam o perfil apresentado na seção 3.2 deste artigo. Práticas relacionadas com a previsão e monitoramento das atividades do projeto, tais como o desenvolvimento de cronogramas, serviços de acompanhamento de prazos e de andamento de tarefas eram consideradas desnecessárias pela diretoria de P\&D e "inibidoras" de criatividade por parte dos desenvolvedores.
Especialmente a visão dos desenvolvedores gerava tensões ao PMO, as quais podem ser assim descritas, segundo as categorias apontadas por Hobbs, Aubry e Thuillier (2008): (1) tensão política - uma vez que o PMO poderia veicular informações sobre a situação das tarefas em um determinado período, poderia expor os desenvolvedores quanto a fragilidades de seu trabalho técnico; (2) tensão de flexibilização e padronização de atividades de planejamento e controle do projeto - a realização dessas atividades implicava em tempo que, segundo os desenvolvedores, desviava seu foco em relação às atividades de projeto propriamente ditas. A terceira tensão foi o "controle sobre a máquina do projeto", a qual surgia de duas formas: (3) uma vez que atividades como a fabricação de peças para protótipos, a coordenação dos departamentos de controle de qualidade e de manufatura / logística para o controle da rastreabilidade dos PMPs do produto, a aquisição de componentes e equipamentos, muitos dos quais importados, não tinham responsáveis bem definidos; e (4) o PMO era visto pelos desenvolvedores como o pessoal que apenas "cobra" e não "gera resultados" que fizessem o projeto avançar.

As tensões eram levadas à diretoria de P\&D da empresa de forma que, por um lado, a diretoria desejava implementar melhor gestão de projetos e, por outro, precisava manter o moral da sua equipe técnica quanto à importância das atividades de desenvolvimento, frente às de gestão. Houve risco de as práticas de GP retrocederem a um nível de mera formalidade, conforme acontecia anteriormente. Porém, enquanto as barreiras representadas pelas tensões (1), (2) e (4) colocavam o PMO e os desenvolvedores em oposição, a tensão (3) foi vista como uma oportunidade para a consolidação do PMO, tendo sido abordada mediante o estabelecimento de um outro conjunto de atividades a serem desempenhadas pelo PMO, conforme ilustrado na Tabela 2. 
Tabela 1. Atividades realizadas pelo PMO.

\begin{tabular}{|c|c|c|c|}
\hline Item & Atividade & $\begin{array}{l}\text { Prática anterior } \\
\text { (Proj. Equip. Médicos) }\end{array}$ & $\begin{array}{l}\text { Descrição do realizado para nível } 1 \\
\text { do PMO (Projetos Aeroespaciais) }\end{array}$ \\
\hline 01 & $\begin{array}{l}\text { Desenvolver o cronograma } \\
\text { detalhado do projeto }\end{array}$ & $\begin{array}{l}\text { Realizado conforme requisitos } \\
\text { 7.3.3 da ISO 9001:2000 }\end{array}$ & $\begin{array}{l}\text { Foi ampliado para a utilização de um cronograma detalhado } \\
\text { do trabalho a ser realizado. }\end{array}$ \\
\hline 02 & $\begin{array}{l}\text { Emitir relatórios } \\
\text { de projeto }\end{array}$ & Não realizado & $\begin{array}{l}\text { Mensalmente são emitidos relatórios de andamento do } \\
\text { projeto. }\end{array}$ \\
\hline 03 & $\begin{array}{l}\text { Acompanhar e comunicar } \\
\text { o andamento das tarefas } \\
\text { do projeto }\end{array}$ & $\begin{array}{l}\text { Realizado conforme requisitos } \\
\text { 7.3.3 da ISO 9001:2000 }\end{array}$ & $\begin{array}{l}\text { Foi ampliado para a utilização de uma WBS do projeto que } \\
\text { é atualizada mensalmente e monitorada semanalmente. }\end{array}$ \\
\hline 04 & $\begin{array}{l}\text { Realizar serviços de } \\
\text { controle de prazos }\end{array}$ & Não realizado & $\begin{array}{l}\text { São confeccionados relatórios mensais de progresso com } \\
\text { datas a serem observadas pelos participantes dos projetos. } \\
\text { As datas são discutidas em reuniões de acompanhamento. }\end{array}$ \\
\hline 05 & $\begin{array}{l}\text { Realizar serviços de } \\
\text { controle de custos }\end{array}$ & Não realizado & $\begin{array}{l}\text { É confeccionado relatório mensal de custos e viabilidade } \\
\text { financeira do projeto com cálculo de TIR e VPL. }\end{array}$ \\
\hline 06 & $\begin{array}{l}\text { Implementação do arquivo } \\
\text { histórico de projeto }\end{array}$ & $\begin{array}{l}\text { Realizado conforme requisito } 7.3 \\
\text { da ISO 9001:2000 }\end{array}$ & $\begin{array}{l}\text { Foi implementado um arquivo pessoal para cada projetista } \\
\text { quanto às suas atividades vinculando-o com cronogramas e } \\
\text { WBS do projeto. }\end{array}$ \\
\hline 07 & $\begin{array}{l}\text { Preparar orçamentos de } \\
\text { projetos }\end{array}$ & Não realizado & $\begin{array}{l}\text { Os projetos passaram a ser orçados de maneira a estabelecer } \\
\text { valores para negociar os contratos de fornecimento. }\end{array}$ \\
\hline 08 & $\begin{array}{l}\text { Comparação do } \\
\text { andamento do projeto } \\
\text { quanto às suas metas }\end{array}$ & Não realizado & $\begin{array}{l}\text { Passou a ser realizado comparando-se os aspectos de prazos } \\
\text { e custos com o planejamento. }\end{array}$ \\
\hline 09 & $\begin{array}{l}\text { Acompanhar e registrar } \\
\text { itens de ação }\end{array}$ & Não realizado & $\begin{array}{l}\text { O cliente dos projetos da área espacial estabelece itens de } \\
\text { ação que são monitorados pelo PMO em termos de prazo e } \\
\text { qualidade. }\end{array}$ \\
\hline 10 & $\begin{array}{l}\text { Suporte às atividades de } \\
\text { controle de qualidade } \\
\text { relativas à normalização }\end{array}$ & Realizado & $\begin{array}{l}\text { Manteve-se a sistemática de monitoramento e identificação } \\
\text { de demandas relacionadas às normas de qualidade. }\end{array}$ \\
\hline 11 & $\begin{array}{l}\text { Organização da } \\
\text { documentacão do projeto }\end{array}$ & $\begin{array}{l}\text { Realizado com base na cláusula } \\
4.2 .3 \text { da ISO } 9001: 2000\end{array}$ & $\begin{array}{l}\text { Manteve-se a estrutura de arquivo utilizada para os projetos } \\
\text { da área médica. }\end{array}$ \\
\hline
\end{tabular}

Tabela 2. Atividades realizadas pelo PMO para remover as barreiras à sua implantação.

\begin{tabular}{|c|c|c|c|}
\hline Item & Atividade & $\begin{array}{l}\text { Prática anterior } \\
\text { (Proj. Equip. Médicos) }\end{array}$ & $\begin{array}{l}\text { Descrição do realizado para nível } 1 \\
\text { do PMO (Projetos Aeroespaciais) }\end{array}$ \\
\hline 12 & $\begin{array}{l}\text { Elaborar relatórios } \\
\text { interdepartamentais }\end{array}$ & Não realizado & $\begin{array}{l}\text { São confeccionados relatórios relacionando pendências de cada } \\
\text { departamento com relação às demandas de prazo e qualidade do projeto. }\end{array}$ \\
\hline 13 & $\begin{array}{l}\text { Ligações com gerentes } \\
\text { funcionais }\end{array}$ & Não realizado & $\begin{array}{l}\text { Os relacionamentos com gerentes funcionais são formalizados por } \\
\text { um comitê de gerenciamento. }\end{array}$ \\
\hline 14 & $\begin{array}{l}\text { Interface de troca de } \\
\text { documentos entre projeto e } \\
\text { produção }\end{array}$ & Não realizado & $\begin{array}{l}\text { Foi centralizada no PMO a troca de desenhos, de esquemas elétricos } \\
\text { e de demais documentos a serem repassados para a manufatura. }\end{array}$ \\
\hline 15 & Monitoramento de PMSs & Não realizado & $\begin{array}{l}\text { São realizadas reuniões semanais cujo objetivo é verificar o } \\
\text { andamento dos PMPs na empresa. }\end{array}$ \\
\hline 16 & $\begin{array}{l}\text { Suporte às atividades de } \\
\text { engenharia e montagem }\end{array}$ & Não realizado & $\begin{array}{l}\text { O PMO centraliza as atividades de monitoramento de PMPs e realiza } \\
\text { atividades de suporte como requisições de compra, estocagem de } \\
\text { peças etc. }\end{array}$ \\
\hline
\end{tabular}


Aos poucos as barreiras foram quebradas à medida que as novas funções agregadas (Tabela 2) foram sendo implantadas e consolidadas. O caráter de "suporte logístico" (ROZENFELD et al., 2006) dessas atividades dentro do escopo do processo de desenvolvimento de produtos garante ao PMO a realização de um grande conjunto de serviços rotineiros que contribuem com a redução do esforço do desenvolvedor em atividades que não são centrais em seu trabalho técnico. O objetivo foi que a satisfação do desenvolvedor com esse tipo de atividade reduzisse a tensão inerente à aplicação das técnicas necessárias para aumentar o grau de controle sobre os prazos e custos das atividades do projeto.

O resultado final foi a introdução de um escritório de projetos cujo escopo original seriam as iniciativas da área espacial na empresa. O esforço de consolidação dessa estrutura permitiu atingir um PMO de nível 1 com atividades realizadas para os estágios inicial e intermediário de atuação do PMO, conforme classificação de V (2001). Um marco foi a passagem da responsabilidade para o PMO pela transferência dos documentos de engenharia para as áreas de fabricação e montagem, assim como pelo acompanhamento da fabricação das peças e pelo estabelecimento de prioridades entre materiais a serem fabricados e /ou aquisicionados para os diferentes projetos. $\mathrm{O}$ pessoal envolvido nos times de projeto passou a estar menos sujeito às pressões de entrega de protótipos nos projetos da área espacial, reduzindo o número de horas extras de montagem necessárias aos protótipos. Essa interface com a fabricação para tratar o conjunto todo dos projetos de desenvolvimento das áreas espacial, militar e médica da empresa, permitiu ao PMO estabelecer práticas relativas a estruturas de nível 2.

Durante o período de sua implantação o PMO desenvolveu e atualizou cronogramas de cerca de 12 diferentes projetos, emitiu relatórios de progresso mensais de 2 projetos ao longo de cerca de 15 meses, intermediou o envio de cerca de 2900 documentos entre o setor de projetos e os setores de manufatura e montagem, coordenou cerca de 25 reuniões semanais de monitoramento dos prazos dos projetos da área espacial, arquivou cerca de 230 diferentes documentos de projetos da área médica e cerca de 520 documentos da área espacial na empresa etc. Foram estabelecidos indicadores de desempenho para as práticas do PMO, cuja explanação detalhada foge ao escopo do presente artigo. Em suma houve redução de 3,5 dias para que cada desenho de fabricação retornasse ao departamento de $\mathrm{P} \& \mathrm{D}$ como peça fabricada no início da implantação do PMO para um estágio atual de 0,08 dia / desenho liberado. As aquisições de itens importados partiram de uma média de 140 dias por item importado para cerca de 50 dias/item. A duração média dos projetos reduziu de cerca de 1800 dias por projeto para cerca de 260 dias/projeto.

\section{Resultados: percepção dos usuários quanto às práticas do Project Management Office - PMO}

Pode-se observar que as atividades listadas na Tabela 1 e na Tabela 2 representam interfaces do PMO constituído com três públicos distintos: a gerência (diretoria de $\mathrm{P} \& \mathrm{D}$ ), os desenvolvedores e os gerentes funcionais de outros departamentos da empresa. Foram realizadas entrevistas com os engenheiros envolvidos nos projetos em andamento na empresa de maneira a verificar o nível de satisfação desse pessoal com relação às atividades realizadas pelo escritório, a qual é relatada a seguir com o apoio da Tabela 3. Esse tipo de análise é denominado por Thomas e Mullaly (2007) como análise da "percepção de satisfação dos stakeholders" sendo uma das maneiras de aferir o valor das práticas de GP para uma determinada empresa. Do ponto de vista da implantação do PMO a análise permitiu identificar o perfil das tensões internas ao departamento de $\mathrm{P} \& \mathrm{D}$ que incidiam sobre o PMO ao final do trabalho de implantação das tarefas apresentadas nas tabelas 1 e 2 .

Para as atividades com as quais os desenvolvedores têm alguma interface foram realizadas afirmações do tipo "os cronogramas desenvolvidos têm auxiliado no andamento da sua atividade dentro do projeto" e solicitada uma avaliação do entrevistado quanto ao seu grau de concordância em relação à afirmação. Assim sendo, atividades como "preparar orçamentos de projetos" não foram objeto de análise por serem serviços realizados diretamente com a alta gerência, e itens como "ligações com gerentes funcionais" não foram analisados por se tratarem de atividade com baixa participação dos desenvolvedores, não sendo estes seu público-alvo. As questões utilizadas na pesquisa constam na Tabela 3.

As questões foram submetidas a 9 desenvolvedores de projetos aeroespaciais, em um universo de 21 usuários das práticas listadas na Tabela 1, perfazendo uma amostra de 43\% do público interno do PMO. A amostra foi distribuída entre diferentes perfis de usuários: (1) pessoal de diferentes áreas técnicas, sendo então distribuídos os entrevistados por especialidade - eletrônica, mecânica, térmica etc.; (2) pessoal envolvido com diferentes projetos, incluindo pessoas de projetos da área médica nos quais há efetivo uso das práticas listadas na Tabela 1; e (3) pessoas que atuam em diferentes estágios dos projetos de maneira a captar informações tanto de engenheiros como de técnicos de montagem especializada.

As questões submetidas aos usuários das práticas do escritório de projetos foram elaboradas na forma de afirmações positivas sobre o trabalho do PMO. Essas afirmações objetivaram causar um impacto no entrevistado quando da realização da pesquisa, de forma a impeli-los de uma tomada de posição sobre o trabalho do PMO: se era considerado exitoso ou não e em que grau. Dessa forma, os 
pesquisados eram questionados sobre o grau de concordância quanto às afirmações listadas na coluna 5 da Tabela 3 segundo a escala: CT - concordo totalmente; $\mathrm{C}$ - concordo; I - indiferente; D - discordo; e DT - discordo totalmente. O questionário foi aplicado por meio de entrevista. Tal escala foi previamente explicada aos pesquisados.

Os dados coletados, de maneira geral, constam na Figura 5.

Demonstra-se uma predominância de respostas que consideram o trabalho do PMO positivo, ou seja, dentro de um campo de concordância com as afirmações da Tabela 3. Enquanto $53 \%$ das respostas afirmaram concordar totalmente ou apenas concordar com as afirmações, indicando uma contribuição efetiva do escritório de projetos no andamento das atividades da engenharia na empresa, cerca de metade desse percentual $(27 \%)$ consideram negativo o trabalho (discordam ou discordam totalmente das afirmações) e $20 \%$ são indiferentes.

A Figura 6 apresenta os resultados da pesquisa quando analisadas as questões ilustradas na Tabela 3 separadamente. Observa-se que a numeração em algarismos romanos apresentada na Figura 6 corresponde à coluna 4 da referida tabela. As práticas do PMO consideradas mais positivas pelos entrevistados foram o "suporte às atividades de engenharia" (X) e "acompanhar e registrar itens de ação" (VII), seguidas de "implementação de arquivo histórico de projeto" (VI), "interface de troca de documentos entre projeto e produção" (V) e "organização da documentação do projeto" (IX). As atividades nas quais houve significativa discordância das afirmações relacionadas à melhoria advinda das práticas do PMO foram "desenvolver cronogramas detalhados dos projetos" (I) e "acompanhar e comunicar o andamento das tarefas do projeto" (IV).

A Figura 7 apresenta uma análise comparativa de três tipos diferentes de atividades realizadas pelo PMO constituído. As atividades do tipo "A", "B" e "C" são identificadas na terceira coluna da Tabela 3. Essa classificação busca seguir aquela realizada por Hobbs e Aubry (2007). O tipo identificado como "A" apresenta atividades com um

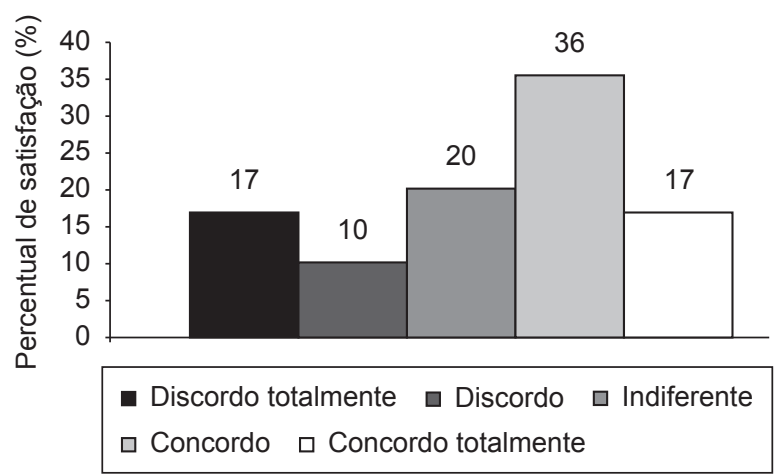

Figura 5. Grau de satisfação do pessoal de projeto com as atividades do PMO constituído.

Tabela 3. Avaliação do trabalho do PMO.

\begin{tabular}{|c|c|c|c|c|}
\hline Item & Atividade & Tipo & & Questão \\
\hline 01 & $\begin{array}{l}\text { Desenvolver o cronograma } \\
\text { detalhado do projeto }\end{array}$ & A & I & $\begin{array}{l}\text { Os cronogramas desenvolvidos têm auxiliado no andamento da sua } \\
\text { atividade dentro do projeto. }\end{array}$ \\
\hline \multirow[t]{2}{*}{02} & Emitir relatórios de projeto & A & II & $\begin{array}{l}\text { Você considera que os relatórios de progresso contribuem com seu } \\
\text { entendimento sobre o status do projeto. }\end{array}$ \\
\hline & & A & III & $\begin{array}{l}\text { O relatório gera informações necessárias para a criação de itens de ação } \\
\text { que venham a melhorar o desempenho do projeto. }\end{array}$ \\
\hline 03 & $\begin{array}{l}\text { Acompanhar e comunicar o } \\
\text { andamento das tarefas do projeto }\end{array}$ & A & IV & $\begin{array}{l}\text { O monitoramento e divulgação das tarefas do projeto têm auxiliado no seu } \\
\text { entendimento do projeto como um todo. }\end{array}$ \\
\hline 08 & $\begin{array}{l}\text { Suporte na interface de troca de } \\
\text { documentos projeto/fabricação }\end{array}$ & $\mathrm{B}$ & $\mathrm{V}$ & $\begin{array}{l}\text { O suporte no intercâmbio de documentos tem auxiliado na redução de } \\
\text { reclamações dos setores produtivos. }\end{array}$ \\
\hline 09 & $\begin{array}{l}\text { Implementação do arquivo } \\
\text { histórico do projeto }\end{array}$ & $\mathrm{C}$ & VI & $\begin{array}{l}\text { Os livros de projetos e arquivos com relatórios e cronogramas têm } \\
\text { contribuído com o andamento dos projetos. }\end{array}$ \\
\hline 12 & $\begin{array}{l}\text { Acompanhar e registrar } \\
\text { itens de ação }\end{array}$ & - & VII & $\begin{array}{l}\text { O monitoramento e divulgação dos itens de ação do projeto têm auxiliado } \\
\text { no seu entendimento do projeto como um todo. }\end{array}$ \\
\hline 14 & Monitoramento de PMPs & B & VIII & O monitoramento dos PMPs contribui para evitar surpresas na montagem. \\
\hline 15 & $\begin{array}{l}\text { Organização da } \\
\text { documentação do projeto }\end{array}$ & $\mathrm{C}$ & IX & A documentação do projeto tem sido útil nas suas atividades cotidianas. \\
\hline 16 & $\begin{array}{l}\text { Suporte às atividades de } \\
\text { engenharia e montagem }\end{array}$ & $\mathrm{B}$ & $\mathrm{X}$ & $\begin{array}{l}\text { As atividades de cadastro, solicitação de compras, recebimento e } \\
\text { armazenagem têm ajudado no planejamento e execução de suas atividades. }\end{array}$ \\
\hline
\end{tabular}




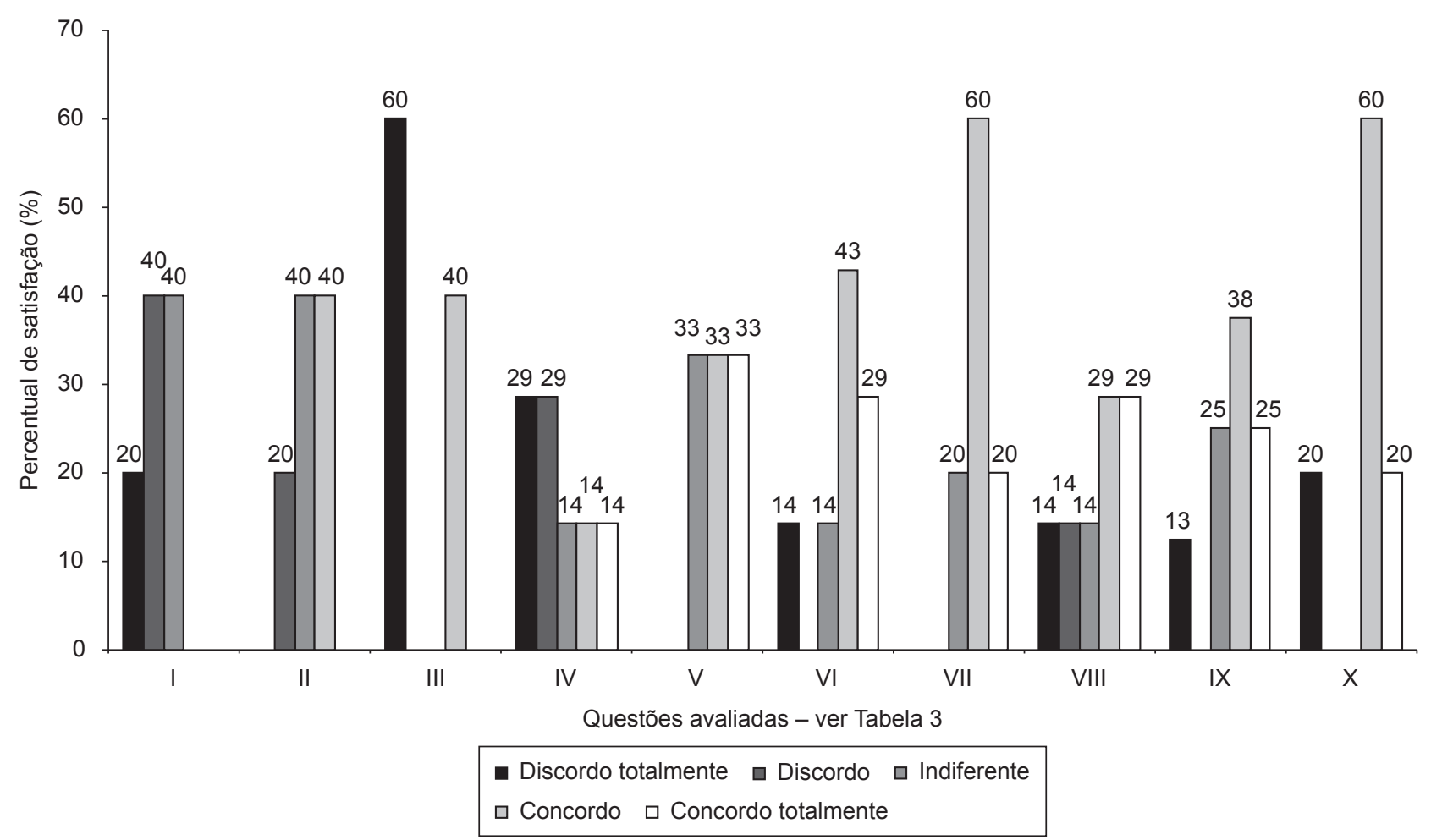

Figura 6. Grau de satisfação do pessoal de projeto com cada atividade pesquisada.

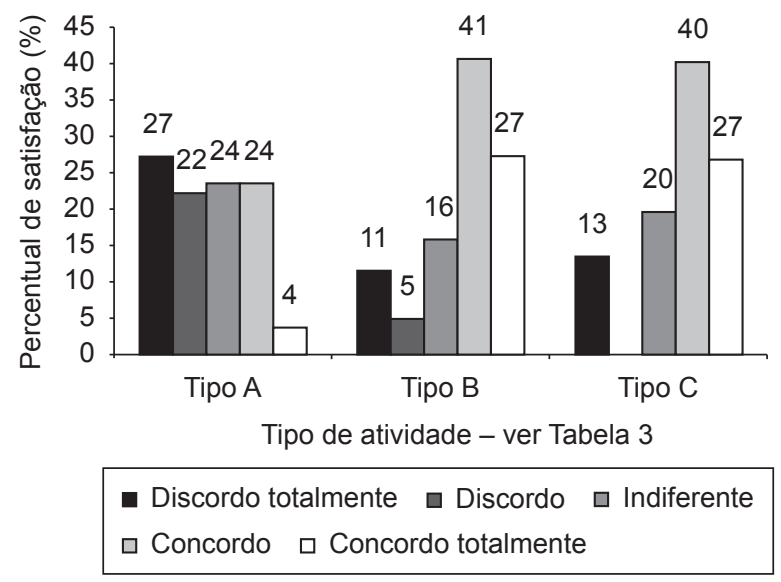

Figura 7.Grau de satisfação dos usuários por tipo de atividade realizada pelo PMO.

perfil relacionado com o monitoramento e controle das atividades de projeto. Atividades do tipo "C" são aquelas que podem ser consideradas de organização e controle de documentos e resultados do projeto, denominadas pelos autores de "aprendizagem organizacional". Atividades de tipo " $\mathrm{B}$ " seriam relativas às atividades logísticas acrescidas ao PMO para a redução das barreiras impostas pela tensão que se estabeleceu entre PMO e desenvolvedores no início do trabalho de aplicação de práticas de GP, conforme já discutido. Essas atividades não estão elencadas pelos autores analisados no presente artigo.
Observa-se na Figura 7 que as atividades realizadas dentro das tipologias "B" e "C" apresentam distribuição similar entre si, com grande percentual de satisfação da equipe de engenheiros da empresa, enquanto que as atividades do tipo "A" apresentam distribuição bem diferenciada com predomínio de respostas "discordo" e "discordo totalmente". O gráfico contribui com a explicação do resultado indicado na Figura 5. Ou seja, os resultados indicam que as atividades com maior caráter de controle do escritório de projetos sobre o trabalho dos engenheiros são consideradas insatisfatórias segundo sua percepção acerca dos serviços oferecidos pelo PMO à empresa. Já as práticas do PMO que dão suporte às atividades cotidianas do pessoal de projeto, tais como o monitoramento da situação de fabricação das peças, das aquisições de componentes etc., são consideradas mais satisfatórias.

Atividades de organização e controle da documentação gerada no setor de engenharia são quase tão satisfatórias quanto às de suporte logístico, sendo, entretanto, maior o grau de respostas que consideram o serviço "indiferente". Esse resultado suporta o entendimento de que o arquivo dos documentos gerados serve como garantia da guarda do material produzido pela engenharia, porém não seja efetivo quanto ao suprimento das demandas de uso do que é arquivado, uma vez que o próprio engenheiro que gera o documento detém backup de seu arquivo e o utiliza quando necessário. Esse, portanto, é um serviço com maior impacto externo que interno à engenharia. 
Em função do que fora exposto neste item, pode-se inferir que, embora o PMO constituído seja considerado bastante positivo (Figura 5) pelo pessoal de projeto, esse grau de satisfação é fortemente determinado pelas atividades de suporte à confecção de protótipos (Figura 6) enquanto as atividades de gerenciamento efetivo do projeto apresentam grau de satisfação consideravelmente inferior às demais (Figura 7).

\section{Considerações finais}

$\mathrm{O}$ artigo apresenta uma experiência de implantação de um escritório de projetos em uma empresa que desenvolvia produtos para a área médica e passou a desenvolver equipamentos também para a área espacial. O PMO foi constituído para prover as demandas contratuais da área espacial mediante o conjunto de serviços apresentado na Tabela 1 sendo complementado pelos serviços expostos na Tabela 2. Estes últimos são o resultado do equacionamento das tensões que surgiram quando da aplicação das atividades previstas na Tabela 1. A estruturação do PMO como resposta a tensões internas relacionadas às práticas de GP está alinhada às contribuições recentes de Hobbs, Aubry e Thuillier (2008).

Ainda com base no referencial teórico desenvolvido ao longo do texto, confirma-se a necessidade de adequação do PMO, como ferramenta gerencial, à cultura da empresa (CALDERINI; CANTAMESSA, 1997), assim como a necessidade de sua adoção gradual (MENDES; ESCRIVÃO FILHO, 2007), e, especialmente, a demanda pela geração de resultados práticos ao longo de sua implantação (MARTINS et al., 2005; RODRIGUES; RABECHINI Jr.; CSILLAG, 2006).

As atividades desenvolvidas pelo PMO foram submetidas aos usuários dos seus serviços para uma avaliação de sua satisfação. As atividades consideradas mais positivas por parte dos entrevistados foram aquelas que dão suporte às suas funções, tais como monitorar dentro e fora da empresa o trânsito de partes e componentes necessários aos protótipos, realizar a entrega de documentos e o recebimento de peças para montagem etc. As atividades do PMO que permitem maior controle quanto às tarefas dos projetos são consideradas menos satisfatórias por parte de engenheiros e líderes de projeto. Esse resultado corrobora com o diagnóstico das tensões de implantação do PMO, já mencionado.

Por outro lado, as atividades consideradas mais positivas pelo pessoal pesquisado dizem respeito exatamente àquelas introduzidas para mitigar o risco das tensões internas prejudicarem a aplicação das práticas de GP. Nesse sentido, à lista de atividades comumente associadas aos PMOs, sumarizadas em Hobbs e Aubry (2007); o artigo contribui com a introdução de atividades de "suporte logístico aos projetos". Esse grupo de atividades traz o PMO para o centro do processo de agregação de valor aos resultados do projeto, especialmente em projetos de desenvolvimento de produtos, nos quais a fabricação de peças e a aquisição de partes e componentes se configuram como etapas críticas para a montagem e teste de protótipos.

Enfim, o quadro geral da pesquisa de satisfação realizada mostra que o PMO é visto, em média, como estrutura que agrega valor aos projetos. $\mathrm{O}$ caso apresentado ajuda a ilustrar como esse resultado pode ser atingido. Ele mostra uma empresa em que havia fortes obstáculos às práticas de GP, enraizados na sua cultura. A implantação gradual de um escritório de projetos, com análise e equacionamento das tensões nele interferentes e com resultados significativos está alterando esta percepção. Portanto, desde que implantadas de maneira criteriosa, as técnicas de gerenciamento de projetos de novos produtos podem trazer benefícios significativos, mesmo em pequenas e médias empresas de alta tecnologia. Para isso, entretanto precisam ser implantados de forma a equacionar as demandas não apenas dos gerentes, mas de todos os envolvidos nos projetos.

Em andamento na empresa e a título de trabalho futuro está a sistematização das atividades do PMO em nível de detalhe tal que permita a publicação dos dados apresentados sumariamente ao longo deste texto e que dizem respeito à melhoria de indicadores de desempenho dos projetos da empresa. 


\title{
Breaking barriers to the project management office implementation in a small and high technology enterprise
}

\begin{abstract}
This paper presents a case of a project management office (PMO) implementation in a medium sized medical industry that started to develop e spatial-related products. The article describes how the entry in a new market have driven the adoption of project management best practices, and solving problems emerged from these practices led to the consolidation of a PMO. The developers were asked whether or not project management (PM) practices were effective for project results. The answers confirm the literature information about the tension due to the introduction of management techniques in technology-based SMEs and added two insights: describe how solving the tensions of the PMO can contribute to its consolidation and demonstrate that the introduction of more operational activities can improve the way the teams involved in projects evaluate the PMO performance.
\end{abstract}

Keywords: High-technology industries. Product development. Project management office.

\section{Referências Bibliográficas}

ASSOCIAÇÃO BRASILEIRA DE NORMAS TÉCNICAS - ABNT. NBR ISO 13485: Produtos para a Saúde - Sistemas de Gestão da Qualidade - Requisitos Particulares para a Aplicação da NBR ISO 9001. Rio de Janeiro, 2000.

ASSOCIAÇÃO BRASILEIRA DE NORMAS TÉCNICAS - ABNT. NBR ISO 9001:2000: Sistemas de Gestão da Qualidade Requisitos. Rio de Janeiro, 2000.

ALI, A. et al. Product innovativeness and entry strategy: impact on cycle time and break-even time. Journal of Product Innovation Mangament, v. 12, n. 1, p. 54-69, 1995.

AUBRY, M.; HOBBS, B.; THUILLIER, D. A new framework for understanding organizational project management through the PMO. International Journal of Project Management, v. 25, n. 4, p. 328-336, 2007.

CALDERINI, M.; CANTAMESSA, M. Innovation paths in product development: an empirical research. International Journal of Production Economics, v. 51, n. 1-2, p. 1-17, 1997.

CARVALHO, M. M. et al. Equivalência e completeza: analise de dois modelos de maturidade em gestão de projetos. RAUSP. Revista de Administração, v. 40, n. 3, p. 289-300, 2005.

CASTRO, H.; CARVALHO, M. M. Project management best practices implementation: critical issues in telecommunication companies. Product: Management \& Development, v. 5, n. 1, p. 41-50, 2007.

CRAWFORD, L. The strategic project office: A guide to improving organizational performance. New York: Marcel Dekker, 2002.

. Developing organizational project management capability: theory and practice. Project Management Journal, v. 36, n. 3, p. 74-97, 2006.

DAI, C. X.; WELLS, W. G. An exploration of project management office features and their relationship to project performance. International Journal of Project Management, v. 22, n. 7, p. 523-532, 2004.

EUROPEAN COMMISSION FOR SPACE STANDARDIZATION. ECSS-M-00B - Space project management - policy and principles. Noordwijk, 2003.

HELDMAN, K. Gerência de Projetos: guia para o exame oficial do PMI. 2 ed. Rio de Janeiro: Editora Campus, 2003. 470 p.
HOBBS, B.; AUBRY, M. A multi-phase research program investigating project management offices (PMOs): the results of phase 1. Project Management Journal, v. 38, n. 1, p. 74-86, 2007.

HOBBS, B.; AUBRY, M.; THUILLIER, D. The project management office as an organizational innovation. International Journal of Project Management, v. 26, n. 5, p. 547-555, 2008.

JUGEND, D. Desenvolvimento de produtos em pequenas e médias empresas de base tecnológica: práticas de gestão no setor de automação de controle de processos. São Carlos, 2006. 125 p. Dissertação (Mestrado em Engenharia de Produção) - Universidade Federal de São Carlos.

JULIAN, J. How project management office leaders facilitate cross-project learning and continuous improvement. Project Management Journal, v. 39, n. 3, p. 43-58, 2008.

KERZNER, H. Gestão de projetos: as melhores práticas. 2 ed. Porto Alegre: Editora BOOKMAN, 2006.

KNIGHT, G. A. Entrepreneurship and strategy in the international SME. Journal of International Management, v. 7, n. 3, p. $155-171,2001$.

LAMBERT, L. R. PMOs e PMPs: existe mágica? Mundo Project Management, v. 1, n. 6, p. 62-65, 2006.

MAN, T. W. Y. et al. The competitiveness of small and medium enterprises: a conceptualization with focus on entrepreneurial competencies. Journal of Business Venturing, v. 17, n. 2, p. 123-142, 2002.

MARCH-CHORDÀ, I.; GUNASEKARAN, A.; LLORIAARAMBURO, B. Product development process in Spanish SMEs: an emmpirical research. Technovation, v. 22, n. 5, p. 301-312, 2002.

MARTINS, A. P. et al. Implantação e consolidação de escritório de gerenciamento de projetos: um estudo de caso. Revista Produção, v. 15, n. 3, p. 404-415, 2005.

MAXIMIANO, A. C. A.; ANSELMO, J. Escritório de gerenciamento de projetos: um estudo de caso. Revista de Administração, v. 41, n. 4, p. 394-403, 2006.

MENDES, J. V.; ESCRIVÃO FILHO, E. Atualização tecnológica em pequenas e médias empresas: propostas de roteiro para aquisição de sistemas integrados de gestão (ERP). Revista Gestão \& Produção, v. 14, n. 2, p. 21-293, 2007. 
MULLALY, M. Longitudinal analysis of project management maturity.

Project Management Journal, v. 36, n. 3, p. 62-73, 2006.

RODRIGUES, I.; RABEQUINI Jr., R.; CSILLAG, J. M. Os escritórios de projetos como indutores de maturidade em gestão de projetos. Revista de Administração, v. 41, n. 3, p. 273-287, 2006.

ROZENFELD, H. et al. Gestão de Desenvolvimento de Produtos. São Paulo: Editora Saraiva, 2006.

SERVA, M.; JÚNIOR, P. J. Observação participante e pesquisa em administração: uma postura antropológica. Revista de Administração de Empresas, v. 35, n. 1, p. 64-79, 1995.

STARBEK, M.; GRUM, J. Concurrent engineering in small companies. International Journal of Machine Tools \& Manufacture, v. 42, n. 3, p. 417-426, 2002.

THIOLLENT, M. Metodologia da pesquisa-ação. São Paulo: Editora Cortez, 1994.

Pesquisa-ação nas organizações. São Paulo: Editora Atlas, 1997.
THOMAS, J.; MULLALY, M. Understanding the value of project management: first steps on an international investigation in search of value. Project Management Journal, v. 38, n. 3, p. 74-89, 2007.

TOLEDO, J. C. et al. Factors influencing new products success in small brazilian medical and hospital equipment firms. In: LOUREIRO, G. \& CURRAN, R. (Org.). Complex Systems Concurrent Engineering: colaboration, technology innovation and sustainability. 1 ed. London: Springer Verlag, 2007. v. 1, p. 657-664.

Fatores críticos de sucesso no gerenciamento de projetos de desenvolvimento de produto em empresas de base tecnológica de pequeno e médio porte. Gestão e Produção, v. 15, n. 1, p. 117-134, 2008.

VALERIANO, D. L. Gerenciamento estratégico e administração por projetos. São Paulo: Editora Makron Books, 2001.

YIN, R. Estudo de caso: planejamento e métodos. 2 ed. Porto Alegre: Bookman, 2004.

\section{Sobre os autores}

\section{Sanderson César Macêdo Barbalho}

OPTO ELETRÔNICA S.A. Departamento de Pesquisa e Desenvolvimento, Rua Joaquim A. R. de Souza, 1071, São Carlos - SP, Brasil, CEP 13563-330 e-mail: sanderson@opto.com.br

\section{Daniel Capaldo Amaral}

Grupo de Engenharia Integrada e Integração, Núcleo de Manufatura Avançada - NUMA, Departamento de Engenharia de Produção

Escola de Engenharia de São Carlos - EESC, Universidade de São Carlos - USP

Av. Trabalhadores São Carlenses, 400, Pq Arnold Schimidt, CEP 13566-590

e-mail: amaral@sc.usp.br

\section{Tiago Sanches Kernbichler}

OPTO ELETRÔNICA S.A. Departamento de Pesquisa e Desenvolvimento, Rua Joaquim A. R. de Souza, 1071, São Carlos - SP, Brasil, CEP 13563-330 e-mail: tiago.sanches@opto.com.br

\section{Eduardo Henrique Richter}

OPTO ELETRÔNICA S.A. Departamento de Pesquisa e Desenvolvimento Rua Joaquim A. R. de Souza, 1071, São Carlos - SP, Brasil, CEP 13563-330 e-mail: eduardo.richter@opto.com.br

\section{Larissa Torres}

Laboratório de Metrologia, Departamento de Engenharia Mecânica Escola de Engenharia de São Carlos - EESC, Universidade de São Carlos - USP Av. Trabalhadores São Carlenses, 400, Pq Arnold Schimidt, CEP 13566-590 e-mail: larissa@yahoo.com.br 